\title{
DISABILITY AS INABILITY
}

\author{
Alex Gregory
}

$\prod$

F WE WERE TO WRITE DOWN all those things that we ordinarily categorize as disabilities, the resulting list might appear to be extremely heterogeneous. Is there really anything in common between motor neuron disease, diabetes, achondroplasia, deafness, a missing lower arm, and cerebral palsy? This apparent heterogeneity gives rise to two related puzzles.

First, if there is nothing all disabilities have in common, this suggests that the concept of disability is not useful when thinking about justice. But this flies wildly against much current practice. For example, many legal systems make reference to disabilities (e.g., non-discrimination law), and many disabled activists and charities perceive themselves as fighting together for a common cause. The concept of disability also figures in various moral concerns that we have, such as when we aim to ensure that disabled people are adequately represented in government and the workplace, or when we worry whether our healthcare policies are fair toward disabled people. Common practices like these seem to presuppose that disabilities are, in some relevant respect, similar. ${ }^{1}$

The second puzzle is that the apparent heterogeneity of disabilities can make it difficult to categorize new or uncertain cases. Should we think of obesity, or disfigurement, or unusual great height, or nut allergies, as disabilities? If we cannot see what disabilities have in common to begin with, it is hard to know how to approach such questions. This issue clearly relates to the first: when we ask whether to count nut allergies as disabilities, part of our interest is surely about the requirements of justice with respect to people with such allergies. But again, without understanding why we sometimes classify disabilities together when

1 One might suggest that we should reject the idea that disabilities must have something in common in order to be relevant from the point of view of justice: disability might be a useful category for thinking about justice only because disabled people-despite having nothing "objective" in common-are often oppressed in similar ways. But to say this is not to reject the reasoning in the text, but instead to endorse it by suggesting a theory of what disabilities have in common: they are oppressed bodily states. I address views of this kind in sections 5 and 6 . 
thinking about justice in the first place, it is unclear how we should approach questions about what else to put into the category.

In the face of these puzzles, we need a theory of what disabilities have in common. Such a theory promises to clarify and vindicate the thought that disabilities are in some respects relevantly similar from the point of view of justice, and would enable us to think more systematically about how to treat uncertain cases such as nut allergies. In this paper I shall defend the view that a particular kind of inability is just what all disabilities have in common. Some might find this conclusion unsurprising, but the theory has some recent detractors and few detailed philosophical defenses. It is beyond the scope of this paper to defend this theory and then also to discuss the practical issues above in the full depth they deserve. But nonetheless, this theory at least puts us in a position to think about those issues more adequately.

Below, in section 1, I provide an attractive version of the inability theory. Then, in sections 2 and 3 , I show how the theory can avoid two central objections. Then, in sections 4 and 5, I show that the theory compares favorably with theories that define disability in terms of well-being, and with theories that define disability in terms of social attitudes. Finally, in section 6, I show that the inability theory is consistent with the social model of disability.

But before we get to all that, I should first clarify our overall topic. When we offer a theory of what it is to be disabled, we might reasonably give different answers depending on exactly what it is that we are seeking. The main thing to say is that I am not seeking a definition of disability that secures some particular predetermined political conclusion. ${ }^{2}$ As I see things, to do this would be to put the cart before the horse. Only by first understanding what different disabilities have in common can we become clearer about what justice requires with respect to disabled people. Our obligations toward disabled people depend on facts about what such lives are like, and as such we need some understanding of the latter issue before we can settle the former.

To this extent, I aim to provide an account of disability that picks out something real in the world - to offer a theory that carves nature at the joints. Such a descriptive theory would show what various disabilities have in common and explain what distinguishes them from other superficially similar phenomena. But although such a theory is descriptive rather than normative, it is nonetheless normatively important insofar as clarifying what disabilities have in common will illuminate the features they have that are relevant for justice.

2 For some related discussion, see Barnes, The Minority Body, 39-42; Haslanger, "Gender and Race," 32-35; Howard and Aas, "On Valuing Impairment," 1115-16; Vehmas, "Philosophy and Science." 
I said above that I would pursue a theory of disability that carves nature at the joints. In fact, we need a theory that carves nature at the joints and whose content is tolerably close to our everyday concept of disability so that we can recognize the theory as a more careful and complete version of that everyday concept. For this reason, I should further clarify that I shall assume that a theory of disability is not the same as a theory of unhealth (neither "disease" nor "illness"). In ordinary thought and talk, having chicken pox, a cold, or a graze do not constitute disabilities. So I shall assume that a theory of disability is not simply the negated expression of a theory of health. ${ }^{4}$

This allows us to immediately set aside bolder versions of the medical model of disability, according to which disabilities are just particular kinds of bodily malfunction. Even if we grant that disabilities involve bodily malfunction, we would need to supplement this view in order to explain what distinguishes disabilities from other bodily malfunctions such as chicken pox or a cold, and in so doing we would end up resorting to one of the views below. For this reason, I shall not address the medical model as a theory in its own right.

An objector might reply that we can understand disabilities merely as permanent bodily malfunctions, in contrast to other temporary kinds of unhealth. ${ }^{5}$ But some kinds of bodily malfunction that are not commonly thought of as disabilities—such as cancer_can be perfectly permanent. Vice versa, and more decisively, some disabilities could be temporary: perhaps there is some virus that paralyzes your legs for a few years, but will eventually work its way out of your system. Plausibly, you are disabled during the intervening period. So this objection fails, and the point stands that a theory of disability is not simply a theory of unhealth.

One final clarification: for ease, throughout this paper I will focus just on physical disabilities. Psychological disabilities (of whatever kind: cognitive, intellectual, emotional, etc.) raise distinctive issues of their own-such as about the difference between a lack of ability and a lack of will—and I cannot hope to

3 For one influential theory, and the distinction between disease and illness, see Boorse, "On the Distinction between Disease and Illness," "Health as a Theoretical Concept," and "A Rebuttal on Health."

4 Moreover, since too much hangs on exactly how we understand "health," I shall leave open whether we should think of disability as a particular kind of poor health or instead as something altogether distinct from poor health. Of course, even in the latter case, some conditions might coincidentally be both disabilities and health conditions. For some related discussion, see Aas, "Disabled-Therefore, Unhealthy?"; Wendell, The Rejected Body; Hull, "Defining Disability," 200; and Silvers, "On the Possibility and Desirability of Constructing a Neutral Conception of Disability," 478.

5 For example, Amundsen, "Against Normal Function," 34-35. 
resolve all such issues here. ${ }^{6}$ But I hope it will be clear that the inability theory at least promises to be extendable as a theory of such disabilities, even if the details will have to wait for another day.

\section{THE INABILITY THEORY}

With our focus clarified, I shall now defend the inability theory. The label indicates the basic idea, which is that disabilities are particular kinds of inability. To specify the view slightly more precisely, I take the inability theory to be the following view:

The Inability Theory: To be disabled is to be less able to do something than is typical, where this degree of inability is partly explained by features of your body that are atypical. ${ }^{7}$

I began by asking what there is in common between motor neuron disease, diabetes, achondroplasia, deafness, a missing lower arm, and cerebral palsy. The inability theory gives us our answer: these things are alike in that they each involve (roughly) some restriction of ability. That is the most natural explanation of why we categorize these things together. And this seems to capture what, in general, all disabilities have in common: some degree of inability in some particular domain. It is very difficult to think of any candidate disability that does not involve any restriction of ability in any domain. To this extent, the inability theory looks like a highly attractive theory of the nature of disability, one that makes clear what it is that apparently heterogeneous disabilities nonetheless have in common. The view also understands disability in a manner that explains its practical significance: disabilities are politically relevant just because the range of people's abilities is politically relevant. Given just how natural the inability theory is, it should be our default view about disability unless we are given good reasons to think it cannot be sustained.

The inability theory promises to help us solve our original puzzles. It promises to clarify why the category of disability is useful for thinking about the requirements of justice. The inability theory tells us that when thinking about the

6 For example, I take it that a theory of disability should tell us that homosexuality is not a disability. To ensure that the inability theory gets that result, we would need to show, for example, that homosexual people are in the relevant sense "able" to conceive children through intercourse. I take it that such a reading of "able" is available, but the issues raised are beyond the scope of this paper.

7 Cf. Amundsen, "Disability, Handicap, and the Environment"; Buchanan, Brock, Daniels, and Wikler, From Chance to Choice, 286-87; Hull, "Defining Disability"; see also the UK's Equality Act 2010, S6(1); Americans with Disabilities Act of 1990, sec. 12102. 
requirements of justice with respect to disabled people, we are really thinking about the requirements of justice with respect to people who lack certain typical abilities: we are asking about our obligations to equalize those levels of ability, and about our obligations insofar as such equalization is not feasible. ${ }^{8}$ Inequalities in ability are clearly relevant from the point of view of justice, and to this extent the inability theory promises to do exactly the job needed: to vindicate, and clarify, our obligations toward disabled people. ${ }^{9}$ The inability theory also promises to help us decide how to classify uncertain cases such as nut allergies, by focusing our attention on whether such conditions can limit ability in the relevant manner.

I shall now clarify four features of the inability theory. First, the inability theory makes reference to our abilities. I am thinking of abilities as capacities of a person to intentionally act in certain ways. So if your body is less able to manufacture some chemical, that is not itself an inability of the relevant kind, though it might produce a disability if it also stops you doing things. ${ }^{10}$ One might further restrict the view so that an ability is a capacity to perform some relatively coarsegrained kind of action, such as playing the piano. In contrast, the view as I develop it permits that capacities to perform relatively fine-grained actions, such as playing a piano with your fingers, count as abilities, and in turn that the absence of such capacities might constitute disabilities. The upside of developing the view in this permissive manner is that it frees us from having to develop some threshold of coarseness of abilities. The main downside is that it entails that we have many disabilities insofar as there are bound to be more abilities you lack, when they are understood in this fine-grained manner. But this worry adds little to existing worries that I address in section 2 about minor disabilities.

Second, the inability theory says that disability consists in being less able to do something than the typical person. ${ }^{11}$ Such degrees of ability are defined in terms of the difficulty or time involved in performing the relevant action. I shall treat a total inability to do something as the limiting case of being "less able" to do something, and so one can be disabled by lacking an ability altogether as well spective on the relevance of abilities for justice, see the capabilities approach in Nussbaum, Women and Human Development; Sen, "Equality of What?" and "Capability and Well-Being." For the capabilities approach as applied to disability, see Nussbaum, Frontiers of Justice; Terzi, "Vagaries of the Natural Lottery?"

Cf. Daniels, Just Health Care.

Cf. Schroeder, "Well-Being, Opportunity, and Selecting for Disability." For one popular perCf. Amundsen, "Disability, Handicap, and the Environment," 107-8.

To this extent, the view avoids those of Elizabeth Barnes's objections (The Minority Body, $16-17,20)$ that treat the view as saying that disabilities consist in total inability rather than reduced levels of ability. 
as by having the ability to some reduced degree. One might worry that some disabilities - such as those that involve general fatigue - might not prevent you from doing any particular thing. ${ }^{12}$ But this is not right: such disabilities might prevent you from, say, working a forty-two-hour week. So long as we remember that the things people can typically do include extended actions, this objection fails: disabilities that involve general fatigue or fluctuations in energy levels plausibly do result in lower levels of ability at various temporally extended tasks. ${ }^{13}$

Third, the inability theory makes reference to what is typical. Here "typical" means "statistically most frequent." We might instead formulate the view with reference to normality, which is a partially evaluative notion. I will not dwell on this choice: everything I say in defense of the inability theory could be redeployed to defend the theory defined in that alternative way. I phrase it in terms of typicality because I find that concept clearer and less dubious than the concept of normality. But if you disagree, you should feel free to rephrase my claims accordingly.

The inability theory actually makes double reference to typicality: it makes reference to what the typical level of ability is, and it also makes reference to what a typical body is like. Both qualifications are needed. If you have typical levels of ability but an atypical body (e.g., you have ginger hair), you are not thereby disabled. Vice versa, if you have atypical levels of ability but a typical body (e.g., you are in jail), you are also not disabled. Disability requires an atypically low level of ability in virtue of a bodily atypicality.

"Typical" here means "typical for a human being of your sex at your stage of development." Humans are not disabled in virtue of lacking the ability to fly; men are not disabled in virtue of lacking the ability to breastfeed; and infants are not disabled in virtue of lacking the ability to talk. ${ }^{14}$ (In principle, we might relativize further, such as to race. But it is hard to find intuitive cases that support further restrictions like this.) Note that I refer to a stage of development-understood biologically—and not merely age. I take it that eighty-year-old humans are at the same stage of development as thirty-year-old humans—adults—and

See Barnes, The Minority Body, 17.

In note $4 \mathrm{I}$ allowed that some conditions might be both diseases and disabilities. The reasoning here favors that thought: some diseases can fatigue us and prevent our completing various extended tasks. This does not undermine the earlier distinction between disability and disease: early-stage cancer, which is not yet impeding your ability to do anything, is a disease but not a disability.

Note that I relativize disabilities to what is typical for human beings, not what is typical for human beings at the present time. So if some strange event rendered most people deaf, deafness would continue to be a disability: it would continue to be atypical for human beings in general, even if not atypical for human beings then alive. 
to that extent both groups are classified as disabled by the same standards. An eighty-year-old with inabilities that are typical for someone their age may nonetheless be disabled if those inabilities are not typical for human adults in general. In turn, the theory rightly entails that many elderly people are disabled.

Further, I take it that typicality requires that your levels of ability, and bodily features, fall within some particular range. To be typical, your body need not be perfectly typical. Thinking of typicality in this manner is natural and also allows the theory to avoid one of Elizabeth Barnes's main objections to the view. Barnes worries that the inability theory is likely to classify being a "petite woman" as a disability, since petite women have bodies that diminish their abilities in some dimensions. ${ }^{15}$ But while petite women might have somewhat atypical bodies and thereby lack some relatively typical abilities, their bodies and ranges of ability are not that atypical. People who are very atypically short and who thereby lack very typical abilities (e.g., to drive a car) might count as disabled, but plausibly merely "petite" women fail to count as disabled precisely because their range of ability falls within the normal range. Petite women are relatively common, at least compared with, for example, people with achondroplasia.

Of course, it will be very hard to draw a sharp line between bodies and abilities that are within the typical range and those that are not: for many disabilities, there is a continuum between them and merely "ordinary" levels of inability. For example, there is a continuum between a nondisabled person with minor problems with their vision and a disabled person who can barely see at all. There is bound to be no precise point along this continuum where one qualifies as disabled, just as there is no precise number of grains of sand that comprises a heap. But this is not a problem for the inability theory: it shows only that the category of disability has some vague boundaries, as seems independently plausible.

The fourth and final feature of the inability theory that I should clarify is that the theory says that to be disabled you must have atypical levels of ability that are partly explained by features of your body that are atypical. Perhaps you (atypically) cannot go outside. And perhaps your body is atypical. But these facts by themselves do not make you disabled: perhaps your abilities are atypical because you are in jail, not at all because of your atypical body. To be disabled, there must be some explanatory connection between the atypical features of your body and the fact that your abilities are atypical.

To this extent, the inability theory claims that disabilities involve inabilities partly explained by your body. But the word "partly" here is crucial. The atypical features of your body need not be the full explanation of why you are less able than others at doing some things. For example, perhaps you cannot read 
War and Peace, and this is atypical, and partly explained by your atypical body: you are blind. But your blindness need not be the complete explanation of your inability to read War and Peace: perhaps your inability is also partly explained by the unavailability of the book in braille. In this case, we can modify your environment-make the book available to you in braille—and thereby raise your level of ability in this context to the typical level. By doing so, we stop you being disabled in this context, even though we have not changed your body. ${ }^{16}$

That is, the inability theory defines disability in terms of inability, where your range of abilities depends both on your body and on your environment. ${ }^{17}$ In some environments bodily differences make no difference, and in other environments those same bodily differences do make a difference. In this way, the theory captures both the attractive thought that whether you are physically disabled depends on your body, but also captures the attractive thought that disability can be heavily influenced by the structure of your environment. The inability theory thereby permits that we should sometimes, or often, address disability by changing environments rather than people. We might reduce levels of disability by making environments more accessible, as well as by making changes to people, such as prosthetics. (I return to some related issues in section 6.)

Having described and clarified the inability theory, I now turn to two objections. Both claim that the inability theory is extensionally inadequate in certain respects, but I shall show how to revise the theory to avoid these implications. I cannot rule out the possibility that the inability theory has some revisionary consequences in some cases for what counts as a disability, but I take those revisionary instances to be rarer and less important than objectors suppose.

\section{OBJECTION: MINOR INABILITY}

In recent works, Elizabeth Barnes and Guy Kahane and Julian Savulescu have objected to the inability theory with similar examples. Barnes writes: "[the view that] to be disabled is to lack a physical ability which most people have [is] a non-starter. Most people can 'roll' their tongues. To not be able to roll your tongue is to lack an ability that most people have. And yet those of us who can't

Of course, merely making this book available in braille is unlikely to stop you being disabled, since you may continue to lack other abilities. But the underlying point stands that disabilities can be minimized and in principle eliminated through changes to our environment.

17 Cf. Hull, "Defining Disability," 206-7; Nussbaum, Women and Human Development, 84-85;

Shakespeare, Disability Rights and Wrongs, 31, 56. 
roll our tongues are not disabled in virtue of that lack of ability."18 Kahane and Savulescu similarly worry about the ability to wiggle one's ears. ${ }^{19}$

There are two possible ways that we might respond to this objection. The first and simplest would be to qualify the theory so that only sufficiently life-changing kinds of inability amount to disabilities. ${ }^{20} \mathrm{I}$ am in principle open to this broad way of developing the inability theory: it is obviously the simplest way to respond to this objection. But there is a lingering worry that this way of developing the inability theory draws an arbitrary line: Why think that whether something is a disability depends in this way upon its impact? A neater view would say that disabilities can have a larger or smaller effect, and then explain away our tendency to say that uninfluential disabilities are not disabilities at all.

Imagine that we are heading for a beer, and I ask you whether you brought any money with you. If you answer in the affirmative, thinking of the £o.10 in your pocket, your answer is true, but nonetheless highly misleading, because it implies that you can afford to buy us beer. For that reason your claim is conversationally inappropriate even though it is strictly true. Or imagine that I ask you whether you have any health problems. If you have a hangnail, that is a health problem, but it would nonetheless be misleading to say that you have a health problem if it is one quite so trivial. Examples like these serve to illustrate Grice's maxim of relation: your assertions ought to be conversationally relevant. ${ }^{21}$ In order to avoid saying things that are misleading, we might sometimes avoid asserting certain truths.

Since this maxim is supposed to be perfectly general, we can also apply it to our talk of disability. Perhaps there are some conditions that are disabilities, but that are not appropriately described as such. Very minor disabilities plausibly fall into this category. After all, when we ask about someone's disability status we are often interested only in disabilities that are relevant for our specific practical purposes, and very often uninfluential disabilities will not be relevant for those purposes. For this reason, we might think that if you are unable to roll your tongue, or wiggle your ears, that is a disability. But saying this is consistent with thinking that we should not describe such disabilities as disabilities, since they are so insignificant and of so little practical relevance. In this respect, such minor disabilities are akin to a health problem like a hangnail: real, but insignificantly tiny.

In short, when we remember independently plausible claims about conver-

Barnes, The Minority Body, 16.

Kahane and Savulescu, "The Welfarist Account of Disability," 45.

Cf. Glover, Choosing Children, 9; Equality Act 2010, s6(1); Americans with Disabilities Act of 1990, sec. 12102.

Grice, "Logic and Conversation." 
sational pragmatics, we can see that the inability theory is perfectly consistent with the thought that it is inappropriate to describe minor inabilities like those above as disabilities. To that extent the inability theory remains unscathed by such supposed counterexamples.

Before we move on, there is an objection to my proposal I should consider. Imagine that you acquire some disability that is, in one sense, comparatively minor-one day you cease to be able to roll your tongue, say. But imagine further that for very idiosyncratic reasons, this makes a big difference to your life: perhaps you are famed for your unusual whistling, and your unusual whistling relied on your ability to roll your tongue. Does the inability theory classify this as a disability? It does. But it might seem that the above Gricean maneuver fails to apply in this case: given your circumstances, this inability is worth mentioning and does have practical relevance. One possibility here is to simply accept that under these circumstances, your inability to roll your tongue could appropriately be called a disability. But more plausibly, the same Gricean maneuver does explanatory work even in this case. Although this inability is clearly worth mentioning, it is nonetheless misleading to highlight its status as a disability. This kind of case is odd precisely because it is a case where something is highly practically significant despite being only minor qua disability: it is a minor restriction on ability with surprisingly wide-reaching consequences. So although this inability is worth mentioning, it would be still be misleading to describe it as a disability given that its significance is not due to its being a significant disability.

\section{OBJECTION: IMPOSED INABILITY}

I now turn to a second objection to the inability theory. To illustrate the problem, imagine that you are a member of a small minority race, and are a victim of direct discrimination on the basis of your race. This racism might reduce the options you have. To that extent, you might be unable to do certain things, where this inability is partly explained by the atypical features of your body. So it seems as though our theory classifies you as disabled. But plausibly, under these circumstances, you are not necessarily disabled. ${ }^{22}$ Similar remarks would apply in many other cases where a bodily minority is constrained by social prejudice. ${ }^{23}$

22 For some discussion, see Barnes, The Minority Body, 18-19; Kahane and Savulescu, "The Welfarist Account of Disability," 34-35.

23 Note that since the inability theory only classifies you as disabled if your body explains your lack of ability, the theory already generates the right results with respect to victims of indirect discrimination. Victims of indirect discrimination may lack certain abilities, but if the discrimination is truly indirect that inability is explained not by their body but instead by some other property they have that happens to correlate with having a body of that kind. 
The best response to this is to qualify the inability theory. We are thinking of disabilities as arising from the way your body combines with your environment. But in the case above, the relevant inability arises not merely from the way your body interacts with your physical environment, but in part from the way your body interacts with other people's attitudes. So to fix the problem, we might modify the inability theory as follows:

The Final Inability Theory: To be disabled is to be less able to do something than is typical, where this degree of inability (1) is partly explained by features of your body that are atypical, and (2) is not explained by anyone's attitudes toward those bodily features.

Here clause 2 serves to explain why the above kind of inability is not a disability. Though your inabilities are explained by atypical features of your body, your inabilities are explained by the attitudes certain people have toward those atypical features of your body. In other cases of disability, the relevant inabilities are not so explained: it is not only because of how people think about paraplegic people that there are some constraints on what such people are able to do. ${ }^{24}$

Some might worry that this qualification rules out too much: Isn't the precise point of the social model of disability that the disadvantages faced by disabled people arise from social oppression? ${ }^{25}$ I shall discuss the social model in section 6. But here there is one key point to make: the social model may say that the disadvantages faced by disabled people arise from society, and are unjust. But to make these claims, we do not need to also say that the disadvantages faced by disabled people arise from attitudes directed toward disabled people's bodies. It is no doubt true that many of the disadvantages faced by disabled people do arise in this way. But when the social model seems persuasive, this is precisely because it does not attribute all the disadvantages faced by disabled people to explicit discrimination. Rather, it also focuses on unjust absences of attention to access. Such failures need not involve anyone disadvantaging disabled people because of their attitudes toward disabled people. In short, we should distinguish between injustice that arises through explicit discrimination, and injustice that arises through a lack of attention. By defining disability as I have above, we must say that some of the constraints on disabled people arise independently of explicit discrimination. That is why the restrictions on disabled people are different than, for example, the restrictions on minority races in racist societies. But saying this is consistent with thinking that many constraints on disabled people 
arise through unjust social choices. So qualifying the inability theory as I do above does not prejudge the issues surrounding the social model.

What should we say in cases where someone's inability is explained by both explicit discrimination and some absence of attention? The inability theory as stated above says that to the extent their inability is not explained by explicit discrimination, it is a disability. To this extent, some inabilities may be constituted in part by disabilities and in part not. For example, imagine that city planners gave very little thought to accessibility for disabled people, but that they did so in part because of discriminatory attitudes (perhaps they thought disabled people just "belong" at home). Under these circumstances, your inability to get to work might be both a disability you have (to the extent that your inability is not wholly explained by their prejudice) but also partially not (to the extent that your inability is partly explained by their prejudice). In some real-world cases, disentangling these factors may be extremely difficult. ${ }^{26}$

This completes my defense of the inability theory. I now turn to compare it with rival theories of disability.

\section{THE WELL-BEING THEORY}

The well-being theory of disability says, roughly, that a disability is a condition that harms you. The view has received its clearest formulation in the work of Guy Kahane and Julian Savulescu. ${ }^{27}$ In its simplest form, the theory says:

The Well-Being Theory: To be disabled is to have a property that harms you.

But this theory is inferior to the inability theory: it faces two key objections. First, this theory says that if something is harmless, it is not a disability. This seems controversial at best: think of apparent disabilities such as achondroplasia and deafness, or what we might think of as minor disabilities, such as missing toes. We might think that these conditions are on balance harmless and are yet disabilities. ${ }^{28}$ In other cases even if the well-being theory gets the right answer, it

26 In some cases, what we should say will hinge on wider questions about what counts as an explanation. Imagine that city planners designed the city this way because they explicitly discriminated, but that had they been fairer minded, they would have reached the same conclusion anyway, for independent reasons. Under these circumstances, it is unclear whether the relevant inability is "explained" by discrimination: it was caused by it, but would have existed regardless. I take this to be a general question about the nature of explanation, not a puzzle specifically for the inability theory.

Kahane and Savulescu, "The Welfarist Account of Disability"; Savulescu and Kahane, "Disability"; see also Harris, "One Principle and Three Fallacies of Disability Studies."

28 For example, on deafness, see Lane, "Do Deaf People Have a Disability?” 
seems to reach it on the wrong grounds: Do we really have to survey paraplegic people on how happy they are in order to gain evidence that paraplegia is a disability? ${ }^{29}$ The well-being theory makes it a difficult empirical question whether paradigm disabilities are in fact disabilities, and this seems surprising at best. ${ }^{30}$

The second problem for the well-being theory is that not all harmful conditions are disabilities. Think, for example, of breaking up with your partner or finding a hair in your sandwich. These things might be bad for you, but are quite clearly not disabilities. I take it that cases like these explain why Kahane and Savulescu claim that only intrinsic harmful properties constitute disabilities: this restriction serves to exclude external harms like these from constituting disabilities. ${ }^{31}$ But this does not solve the underlying problem: there are plenty of intrinsic harmful properties that are not disabilities, such as grumpiness or a mild hangover. Kahane and Savulescu still further qualify the theory so that disabilities are only constituted by stable intrinsic harmful properties. ${ }^{32}$ But this is wrong in both directions: your grumpy personality might be permanent, and your disabling paralysis might be temporary.

Throughout their papers, Kahane and Savulescu positively admit that their theory has counterintuitive implications like these. ${ }^{33}$ Kahane and Savulescu think that we should focus on finding a theory of disability that does interesting ethical work, even if we thereby end up with a theory that has some surprising implications about which things count as disabilities. But there is no need to choose between these two goals: the inability theory shows that the concept of disability is one that does interesting ethical work without the need for radically revising standard disability classifications.

The amount of freedom we have is clearly a topic of central political importance, and our range of abilities is clearly relevant for the amount of freedom we have. In this way, the inability theory understands disability in a manner that

29 Do I here assume some hedonistic theory of well-being? No. Even if happiness is not the only contributor to well-being, it is surely $a$ contributor, and that is enough to make it an open empirical question whether paraplegic people might on balance be living lives that are relatively high in well-being because they are happy. Barnes, The Minority Body, 11. For interesting data on the happiness of disabled people, see Albrecht and Devlieger, "The Disability Paradox"; Boyd et al., "Whose Utilities for Decision Analysis?"; Daniels, Rose, and Daniels Zide, "Disability, Adaptation, and Inclusion"; Sackett and Torrance, "The Utility of Different Health States as Perceived by the General Public"; Ubel, Loewenstein, and Jepson, "Whose Quality of Life?”; Ubel and Loewenstein, "Pain and Suffering Awards."

31 Kahane and Savulescu, "The Welfarist Account of Disability," 24-25.

32 Kahane and Savulescu, "The Welfarist Account of Disability," 24-25.

Kahane and Savulescu, "The Welfarist Account of Disability," 25-33. 
connects it to a topic of central political importance. Investigating the exact practical implications of disability, as the inability theory understands it, would take us far afield, but we can at least note the obvious points to be explored. (i) The inability theory may suggest that disabilities are intrinsically bad if we think there is something good about freedom itself. To assess this, we would need to ask whether there really is intrinsic value to having more abilities. ${ }^{34}$ (ii) The inability theory may suggest that disabilities are instrumentally bad insofar as there are often instrumental advantages to having more abilities. To assess this, we would need to ask whether there are always instrumental benefits to having more abilities. ${ }^{35}$ Moreover, we would need to ask whether there are sometimes instrumental benefits to having fewer abilities. ${ }^{36}$

In short, the inability theory captures the thought that disabilities are highly ethically significant, though it inevitably leaves us with theoretical work to do. To that extent, Kahane and Savulescu are wrong when they imply that a theory of disability can capture the ethical significance of disability only by radically revising our ordinary concept. The inability theory captures the ethical significance of disability while nonetheless remaining tolerably close to our everyday conception of disability. In contrast, the well-being theory might capture something of ethical relevance, but only by radically revising ordinary classifications of disability. Pace Kahane and Savulescu, this is a theoretical cost we do not need to pay.

\section{CONVENTIONALIST THEORIES}

I now turn to a second rival theory of disability, which I label "conventionalist." Conventionalist theories claim that disabilities are not intrinsic states of people but instead socially constructed properties that are generated by the attitudes of some person or people. ${ }^{37} \mathrm{I}$ address two such theories.

Our first conventionalist theory says that you are disabled if your society categorizes you as disabled. Call this:

See, e.g., Dworkin, The Theory and Practice of Autonomy, 62-81, esp. 80.

35

Goering, "'You Say You're Happy, but ...," 130; Moller, "Wealth, Disability, and Happiness," 198-99; Schroeder, "Health, Disability, and Well-Being," 224-25; Silvers, "On the Possibility and Desirability of Constructing a Neutral Conception of Disability," 479-80; Wasserman and Asch, "Understanding the Relationship between Disability and Well-Being," 149-52.

Schwartz, "Self-Determination" and The Paradox of Choice; Silvers, "On the Possibility and Desirability of Constructing a Neutral Conception of Disability," 482. 
Simple Conventionalism: To be disabled is to be categorized as disabled by society.

Simple conventionalism is unsustainable. ${ }^{38}$ Whether you are disabled does not depend on the attitudes of society, as illustrated by the possibility of a sailor who is shipwrecked and washes up ashore alone on a desert island, paralyzed from the waist down, with no one aware of her disability. Vice versa, imagine that a celebrity becomes a recluse and hides away without any human contact. A rumor goes around to the effect that they have become a recluse in virtue of a disability. Does that rumor suffice to make it true that they are disabled? No. Further investigation might, under these circumstances, show the rumor to be wrong, and this would not be possible if the existence of the rumor sufficed for its own truth. ${ }^{39}$

The point is obviously not that this kind of error is common, but instead that there is no reason to think that society is infallible at identifying disability. ${ }^{40} \mathrm{We}$ look in the wrong place if we try to determine whether someone is disabled by looking at people's attitudes toward them. Our attitudes toward people aim to be responsive to facts about how those people really are, and our attitudes can be mistaken precisely because the facts are independent of what we think..$^{41}$ Equally, if we come across some difficult case where it is unclear whether to classify something as a disability (e.g., deafness), it would be a mistake to try to resolve that uncertainty by surveying what people think of that condition: their views on such matters are formed only in light of other fallible views they have about the nature of the condition and the best way to think of disability. ${ }^{42}$ In short, simple conventionalism is implausible for the reason that society can make mistakes about who is disabled.

In her recent book, Elizabeth Barnes objects to a theory along similar lines, but goes on to suggest a nearby theory as a superior replacement. ${ }^{43}$ On her theory-our second conventionalist theory-whether you are disabled is socially

38 See also Howard and Aas, "On Valuing Impairment," 1123-24.

39 Similar counterexamples would undermine the nearby theory that classifies people as disabled according to whether they themselves think they are disabled. Some people might not know they are disabled: think of small children, or people with anosognosia, such as those with Anton-Babinski syndrome. Vice versa, someone might think that they are disabled when they are not (perhaps if they have succumbed to an extreme practical joke). Cf. Stone, "Reactions to Invisible Disability"; Wendell, The Rejected Body, 25-26.

Bury, "Defining and Researching Disability," 30 ; Howard and Aas, "On Valuing Impairment," 1123; Shakespeare, Disability Rights and Wrongs, 76-77.

Cf. Shakespeare, Thompson, and Wright, "No Laughing Matter," 3.

Barnes, The Minority Body, 28-38. 
constructed, but not quite so directly as simple conventionalism suggests. She writes:

A person, $S$, is physically disabled in a context $C$, iff:

(i) $S$ is in some bodily state $x$

(ii) The rules for making judgements about solidarity employed by the disability rights movement classify $x$ in context $C$ as among the physical conditions that they are seeking to promote justice for. ${ }^{44}$

The idea is that whether you are disabled does depend on the attitudes of one part of society, namely, the disability rights movement. But their attitudes alone do not determine whether you are disabled: what matters is whether you in fact have the general kind of body that they aim to represent. To this extent, Barnes's theory allows for some mistakes about disability: perhaps you do have the kind of body that the disability rights movement aims to represent, but perhaps noone knows that this is true. Vice versa, perhaps you do not in fact have the kind of body that the disability rights movement represents, but people nonetheless treat you as disabled. The view also makes room for a further kind of mistake. Barnes's theory makes reference to the rules that the disability rights movement uses to "make judgements about solidarity" - presumably, the rules they implicitly use to classify things as disabilities. And "this allows that the disability rights movement can be mistaken - even systematically mistaken - about whether a given physical condition is a disability. And that is because they can deploy their own rules incorrectly." 45

But though it is a vast improvement on simple conventionalism, Barnes's theory nonetheless fails for similar reasons. Just as the disability rights movement might make mistakes about which bodies are disabled, and just as the disability rights movement might make mistakes in deploying their rules as to which kinds of bodies count as disabled, they can also be mistaken in the rules they use for classifying people as disabled or not. In turn, they might make mistakes about which conditions they are seeking to promote justice for.

One way to see this is to note that Barnes endorses the theory above while criticizing various rival theories (such as the inability theory) on the grounds that they have implausible implications. ${ }^{46}$ But such criticism is beside the point if Barnes's own theory is correct. If Barnes's own theory is correct, the only way to evaluate any other theory of disability is simply to ask whether it is the one endorsed by the disability rights movement. If they endorse the inability theory

44 Barnes, The Minority Body, 46.

45 Barnes, The Minority Body, 46-47.

46 Barnes, The Minority Body, 13-38. 
as the way to decide whether someone is disabled or not, then that theory must be correct, regardless of what implausible implications it might have. So as an ad hominem point, Barnes is inconsistent when she subscribes to her theory but evaluates other theories on grounds that are independent of the views of the disability rights movement. And more substantively, insofar as we agree with Barnes - when she is in her critical mode - that theories of disability are evaluable independently of whether they happen to coincide with the views of the disability rights movement, then Barnes's theory has to be mistaken.

Moreover, Barnes's theory makes it impossible for the disability rights movement to be mistaken about the general nature of disability. But this is implausible: the movement is formed of human beings who can think in confused or ignorant ways. ${ }^{47}$ Insofar as they do that collectively, they might deploy rules for classifying people as disabled that are themselves confused or that presuppose falsehoods. For example, perhaps the disability rights movement holds mistaken views about human nature that wrongly inform their views of disability. Or perhaps the movement holds views about disability that are confusedly influenced by their views about evolution. Or perhaps the movement is primarily constituted by men, or by younger people, and as a result the movement employs rules for classifying people as disabled that are wrongly insensitive to issues that primarily affect women or the elderly. ${ }^{48}$

Just as with simple conventionalism, my point is not that the disability rights movement is actually mistaken about the nature of disability. The people who compose that movement might well know a lot about disability, and the wisdom of crowds might help the movement as a whole overcome the mistakes of some of its individual members. But it is nonetheless true that the movement is composed of fallible individuals, who are therefore collectively fallible about the nature of disability. But on Barnes's theory, the disability rights movement is infallible about the nature of disability. This is surely wrong, and so Barnes's theory must be false.

I conclude that conventionalist theories like those above are mistaken, be-

See also Lim, "Disabilities Are Also Legitimately Medically Interesting Constraints on Legitimate Interests," 982-87.

48 At least this objection to Barnes also carries across to Chong-Ming Lim's modified version of her theory ("Disabilities Are Also Legitimately Medically Interesting Constraints on Legitimate Interests"), according to which disabilities are (roughly) states that the disability rights movement represents and which meet further conditions, such as that they limit your functionings and are of medical interest (987). Whatever the other merits of Lim's view, it shares with Barnes's the claim that the views of the disability rights community place necessary conditions on disability, and that is mistaken: again, their rules might be defective in ways that lead them to neglect conditions that ought to be recognized as disabilities. 
cause they cannot make adequate room for mistakes about the nature of disability. This is one respect in which the social model can seem attractive, since it stresses the social nature of disability while nonetheless allowing for an important role for the body to play, namely in constituting whether an individual has an impairment. To this theory I now turn.

\section{THE SOCIAL MODEL}

The social model of disability was most famously laid out in the Union of the Physically Impaired Against Segregation's (UPIAS) "Fundamental Principles of Disability" document. In its most famous passage, it says:

In our view it is society which disables physically impaired people. Disability is something imposed on top of our impairments by the way we are unnecessarily isolated and excluded from full participation in society. Disabled people are therefore an oppressed group in society. To understand this it is necessary to grasp the distinction between the physical impairment and the social situation, called "disability," of people with such impairment [sic]. Thus we define impairment as lacking part of or all of a limb, or having a defective limb, organ or mechanism of the body; and disability as the disadvantage or restriction of activity caused by a contemporary social organisation which takes no or little account of people who have physical impairments and thus excludes them from participation in the mainstream of social activities. ${ }^{49}$

As this passage suggests, the core part of the social model of disability is the distinction between impairment and disability, where impairments are defined in terms of bodily "defects," and disabilities are the socially mediated effects of such impairments. ${ }^{50}$ Morris gives some helpful illustrations: "an inability to walk is an impairment, whereas an inability to enter a building because the entrance is up a flight of steps is a disability. An inability to speak is an impairment but an inability to communicate because appropriate technical aids are not made available is a disability. An inability to move one's body is an impairment but an inability to get out of bed because appropriate physical help is not available is a disability." ${ }^{\text {51 }}$ As these examples make clear, it is crucial for the social model that

Cited in Oliver, Understanding Disability, 22.

50 See, e.g., Barnes, Disabled People in Britain and Discrimination; Finkelstein, Attitudes and Disabled People; Oliver, Understanding Disability; and cf. the distinction between sex and gender.

51 Morris, Independent Lives? $\mathrm{x}$. 
disabilities are generated not by impairment alone, but instead by the combination of impairment and environment. ${ }^{52}$

The basic ideas behind the social model are relatively clear. But pinning down the exact content of the theory is more difficult. ${ }^{53}$ I will set aside three versions of the social model, and then focus in more depth on a fourth.

First, there is:

The Minimalist Social Model: Whether you are disabled depends on your environment, not just your body.

Anyone who signs up to the social model in any form presumably signs up to this minimal claim. The minimalist social model is not merely consistent with the inability theory, but in fact positively entailed by the inability theory. As I explained when introducing the inability theory, it permits that disability depends on the environment: it says that disability involves atypical levels of ability that are partly explained by your body but also partly explained by your environment. So if we think of the social model as the minimalist social model, then the inability theory and the social model are certainly not competitors and I subscribe to both.

I address the next two options together:

The Causal Social Model: (Very) often, the difficulties faced by disabled people arise from unjust choices, such as unjust absences of attention or explicit discrimination.

The Normative Social Model: (Very) often, we should solve the difficulties faced by disabled people by changing the environment, not their bodies.

I tend to think that these claims go beyond the minimalist social model in ways that more accurately reflect the actual commitments of adherents of the social model. But despite their interest, my arguments in this paper do not directly bear on these claims. The inability theory is a theory of what disabilities are, and not a descriptive claim about human history or a normative claim about how we should henceforth organize society. To that extent, it does not directly support or undermine the two claims above.

I will now turn to our final and most relevant interpretation of the social model:

Cf. World Health Organization, "International Classification of Impairments, Disabilities, and Handicaps," 28; and Disability Discrimination Act 1995.

53 Cf. Oliver, Understanding Disability, 41: "[The social model of disability] is not a social theory of disability and it cannot do the work of social theory." 
The Social Theory: To be disabled is to be harmed or restricted by social response to impairment. ${ }^{54}$

I label this version of the view the social theory since it is designed to be a complete theory of the nature of disability that competes with the inability theory. And I take it that this theory does seem to reflect the UPIAS quote above: it maintains a distinction between impairment and disability, and says that the latter should be defined as the socially mediated consequences of the former.

If we understand the social model in this way, how should we adjudicate between it and the inability theory? To make progress with this question, let us first consider a possible objection to the social theory. Again, imagine that a sailor is shipwrecked, and washes up alone on a desert island, paralyzed from the waist down. Is she thereby disabled? Ordinary usage of the label "disabled" would suggest that she is, but according to the social theory above, she is not. Is this a problem for the social theory? I assume that defenders of the theory will say that it is not. They will say that the theory functions partly to stipulate a use for the label "disabled," rather than to track common usage. Defenders of the social theory ought to be happy to claim that the sailor is not disabled, precisely because — as they use the label—being disabled requires that you interact with society in a certain manner.

Nonetheless, we might still want to say something about the condition that the sailor does have, and that they seem to have in common with someone who is in England and paralyzed in the same way. According to the social theory, the thing these individuals have in common is their impairment rather than their disability. This serves to remind us that the social theory relies heavily on the notion of impairment. It relies on that notion to capture commonsense thoughts about things people can have in common across different social contexts.

The social theory also relies on the concept of impairment in a second way: we cannot simply define disabilities as restrictions or disadvantages caused by society, since that would fail to distinguish disability from other socially stigmatized characteristics such as gender or race. ${ }^{55}$ Defenders of the social model should claim that disability is distinct from other dimensions of oppression because it involves social response to impairment rather than to other bodily features.

In fact, defenders of the social theory are likely to require the concept of imPolicy, 176; Howard and Aas, "On Valuing Impairment," 1118; Shakespeare, Disability Rights and Wrongs, 76-77. 
pairment for a third purpose: in order to articulate their desires. We might want to bring about a world where disabled people do not suffer from discrimination. But if "disability" is defined so that disabled people by definition suffer from discrimination, this goal would be incoherent. Defenders of the social model can express the relevant hope in a different manner: by saying that we should bring about a world where people with impairments do not face discrimination.

So the social theory depends heavily on the concept of impairment. But what is an impairment? The answer to this question is not wholly clear. ${ }^{56}$ We might naturally turn to the UPIAS quotation above. It defines impairment as "lacking part of or all of a limb, or having a defective limb, organ or mechanism of the body." ${ }^{57}$ But if this is the right way to think about impairment then, surprisingly, the social theory inherits the problems of the medical model of disability with which I began. ${ }^{58}$ When we think about impairment, it would be odd to class having chicken pox, a cold, or a graze as impairments. But this is what we must do if we claim that any bodily malfunction is an impairment. When we think about what our sailor has in common with a paraplegic person in England, it does not seem to be something also shared by anyone with a cold.

Alternatively, sometimes impairment is defined not as a malfunction, or as a deficiency of any other kind, but instead as a mere difference. For example, Simo Vehmas characterizes the social model so that it treats an impairment as an "organic anomaly," and this way of thinking fits well with those who think of disabilities as mere differences that are subject to prejudice. ${ }^{59}$ But this way of thinking of impairment also seems unsustainable. For example, the sprinter Usain Bolt is not leg impaired, despite having biologically anomalous legs. And again, when we think about what our sailor has in common with a paraplegic person in England, it does not seem to be something shared by Usain Bolt.

So it is not clear exactly how we should define impairment. ${ }^{60}$ But since the

Cf. Shakespeare, Disability Rights and Wrongs, 10-19; and note that neither the Equality Act 2010: Guidance (esp. A3) nor the Americans with Disabilities Act of 1990 offers a definition of the term.

One classic objection to the social model is that it understates the difficulties raised by impairment alone, by attributing all of the difficulties faced by disabled people to society (e.g., French, "Disability, Impairment or Something in Between?"). Whatever its merits, this worry is distinct from mine. See also, e.g., Crow, "Including All Our Lives," 211. Cf. Hughes and Paterson, "The Social Model of Disability and the Disappearing Body," 329. Vehmas, "Ethical Analysis of the Concept of Disability," 210-11; see also World Health Organization, "International Classification of Impairments, Disabilities, and Handicaps," 27. 
social theory relies heavily on the notion of impairment, the social theory is at best radically incomplete. It cannot adequately capture what our sailor has in common with a paraplegic person in England, and cannot adequately specify what distinguishes disabilities from other kinds of social disadvantage such as gender. Of course, we could rescue the social model from this objection by deploying the inability theory as our theory of impairment. ${ }^{61}$ If we did this, any remaining disagreement between the inability theory as I have presented it, and this view, would be purely verbal: about whether to define "impairment" as inability, and use "disability" to refer to the socially mediated costs of that inability, or whether to instead define "disability" as inability, and to refer to the socially mediated costs of that inability using some other label. If others want to insist on using terminology in the former way, I am happy to do so: I cannot see that anything deep hangs on this.

In summary, we should distinguish four different versions of the social model. The minimalist social model is positively entailed by the inability theory. The causal and normative social models are independent of the inability theory. And the social theory is plausible only if combined with the inability theory. I therefore conclude that the inability theory is consistent with the social model of disability in any plausible form.

\section{CONCLUSION}

In this paper I have argued that we should define disability as a particular kind of inability. We should endorse:

The Final Inability Theory: To be disabled is to be less able to do something than is typical, where this degree of inability (1) is partly explained by features of your body that are atypical, and (2) is not explained by anyone's attitudes toward those bodily features.

This theory can overcome the objections raised by its opponents, is superior to the well-being theory and to conventionalist theories of disability, and is consistent with the social model of disability. I leave open that there might yet be still

\footnotetext{
"The Social Model of Disability"). But if anything, this would make the case of the shipwrecked sailor all the more problematic since now we cannot say that she is disabled or that she is impaired and yet we still should have some term to capture what she has in common with a paraplegic person in England.

61 For example, Howard and Aas defend the social model, and understand impairment as a kind of malfunction - but they later allow that we might need to understand impairments as only those malfunctions that limit activity ("On Valuing Impairment," 1120).
} 
other as yet unvoiced objections to the inability theory, but until they are articulated we should tentatively endorse the inability theory of disability. ${ }^{62}$

University of Southampton a.m.gregory@soton.ac.uk

\section{REFERENCES}

Aas, Sean. "Disabled-Therefore, Unhealthy?" Ethical Theory and Moral Practice 19, no. 5 (November 2016): 1259-74.

Albrecht, Gary L., and Patrick J. Devlieger. “The Disability Paradox: High Quality of Life against All Odds.” Social Science and Medicine 48, no. 8 (April 1999): 977-88.

Americans with Disabilities Act of 1990, Pub. L. No. 101-336, 104 Stat. 328 (1990). Amundsen, Ron. "Against Normal Function." Studies in History and Philosophy of Biological and Biomedical Sciences 31, no. 1 (March 2000): 33-53.

- "Disability, Handicap, and the Environment." Journal of Social Philosophy 23, no. 1 (March 1992): 105-18.

Barnes, Colin. Disabled People in Britain and Discrimination. London: Hurst and Co., 1991.

Barnes, Elizabeth. The Minority Body. Oxford: Oxford University Press, 2016.

Bickenbach, Jerome E. Physical Disability and Social Policy. Toronto: University of Toronto Press, 1993.

Boorse, Christopher. "Health as a Theoretical Concept." Philosophy of Science 44, no. 4 (December 1977): 542-73.

_. "On the Distinction between Disease and Illness." Philosophy and Public Affairs 5, no. 1 (Autumn 1975): 49-68.

- "A Rebuttal on Health." In What Is Disease? Edited by James M. Humber and Robert F. Almeder, 1-134. Totowa, NJ: Humana Press, 1997.

Boyd, Norman F., Heather J. Sutherland, Karen Z. Heasman, David L. Tritchler, and Bernard J. Cummings. "Whose Utilities for Decision Analysis?" Medical Decision Making 10, no. 1 (February 1990): 58-67.

Brownlee, Kimberley, and Adam Cureton, eds. Disability and Disadvantage. Oxford: Oxford University Press, 2011

Buchanan, Allen, Dan W. Brock, Norman Daniels, and Daniel Wikler. From

62 I have too many people to thank for helpful comments on this paper, but I should record special thanks to the two excellent referees for this journal, who gave extremely generous feedback. 
Chance to Choice: Genetics and Justice. Cambridge: Cambridge University Press, 2002.

Bury, Mik. "Defining and Researching Disability: Challenges and Responses." In Exploring the Divide, edited by Colin Barnes and Geoff Mercer, 18-38. Leeds: The Disability Press, 1996.

Crow, Liz. "Including All Our Lives." In Encounters with Strangers: Feminism and Disability, edited by Jenny Morris. London: Women’s Press, 1996.

Daniels, Norman. Just Health Care. Cambridge: Cambridge University Press, 1985.

Daniels, Norman, Susannah Rose, and Ellen Daniels Zide. "Disability, Adaptation, and Inclusion." In Brownlee and Cureton, Disability and Disadvantage, $54-85$.

Disability Discrimination Act 1995. Chapter 50. London: HMSO.

Dworkin, Gerald. The Theory and Practice of Autonomy. Cambridge: Cambridge University Press, 1988.

Equality Act 2010. London: HMSO. http://www.legislation.gov.uk/ukpga/2010/ $15 /$ contents.

Finkelstein, Victor. Attitudes and Disabled People. New York: World Rehabilitation Fund, 1980.

French, Sally. “Disability, Impairment or Something in Between?” In Disabling Barriers —Enabling Environments, edited by John Swain, Vic Finkelstein, Sally French, and Mike Oliver, 17-25. London: Sage Publications, 1993.

Glover, Jonathan. Choosing Children. Oxford: Oxford University Press, 2008.

Goering, Sara. “'You Say You're Happy, but ...': Contested Quality of Life Judgments in Bioethics and Disability Studies." Bioethical Inquiry 5, nos. 2-3 (June 2008): 125-35.

Grice, Paul. "Logic and Conversation." In Syntax and Semantics 3: Speech Acts, edited by Peter Cole and Jerry L. Morgan, 41-58. New York: Academic Press, 1975.

Harris, John. "One Principle and Three Fallacies of Disability Studies." Journal of Medical Ethics 27, no. 6 (December 2001): 383-87.

Haslanger, Sally. "Gender and Race: (What) Are They? (What) Do We Want Them to Be?" Noûs 34, no. 1 (March 2000): 31-55.

Howard, Dana, and Sean Aas. "On Valuing Impairment." Philosophical Studies 175, no. 5 (May 2018): 1113-33.

Hughes, Bill, and Kevin Paterson. "The Social Model of Disability and the Disappearing Body: Towards a Sociology of Impairment." Disability and Society 12, no. 3 (1997): 325-40. 
Hull, Richard. "Defining Disability: A Philosophical Approach." Res Publica 4, no. 2 (September 1998): 199-210.

Kahane, Guy, and Julian Savulescu. "The Welfarist Account of Disability." In Brownlee and Cureton, Disability and Disadvantage, 14-53.

Lane, Harlan. "Do Deaf People Have a Disability?" Sign Language Studies 2, no. 4 (Summer 2002): 356-79.

Lim, Chong-Ming. "Disabilities Are Also Legitimately Medically Interesting Constraints on Legitimate Interests." Mind 127, no. 508 (October 2018): 9771002.

Moller, Dan. "Wealth, Disability, and Happiness." Philosophy and Public Affairs 39, no. 2 (Spring 2011): 177-206.

Morris, Jenny. Independent Lives? Community Care and Disabled People. Basingstoke: Palgrave Macmillan, 1993.

Nussbaum, Martha. Frontiers of Justice: Disability, Nationality, Species Membership. Cambridge, MA: Harvard University Press, 2006.

- Women and Human Development: The Capability Approach. Cambridge: Cambridge University Press, 2000.

Oliver, Michael. Understanding Disability: From Theory to Practice. Basingstoke: Macmillan, 1996.

Sackett, David L., and George W. Torrance. "The Utility of Different Health States as Perceived by the General Public." Journal of Chronic Diseases 31, no. 11 (1978): 697-704.

Savulescu, Julian, and Guy Kahane. "Disability: A Welfarist Approach." Journal of Clinical Ethics 6, no. 1 (March 2011): 45-51.

Schroeder, Andrew. "Health, Disability, and Well-Being." In The Routledge Handbook of Philosophy of Well-Being, edited by Guy Fletcher, 221-32. London: Routledge, 2016.

—. "Well-Being, Opportunity, and Selecting for Disability." Journal of Ethics and Social Philosophy 14, no. 1 (2018): 1-27.

Schwartz, Barry. The Paradox of Choice. New York: Harper Perennial, 2004. . "Self-Determination: The Tyranny of Freedom." American Psychologist 55, no. 1 (January 2000): 79-88.

Sen, Amartya. "Capability and Well-Being." In The Quality of Life, edited by Martha Nussbaum and Amartya Sen, 30-53. Oxford: Clarendon Press, 1993.

_. "Equality of What?" In Tanner Lectures on Human Values, vol. 1, edited by Sterling M. McMurrin, 195-220. Cambridge: Cambridge University Press, 1980.

Shakespeare, Tom. Disability Rights and Wrongs. Abingdon: Routledge, 2006.

Shakespeare, Tom, Sue Thompson, and Michael Wright. "No Laughing Matter: 
Medical and Social Experiences of Restricted Growth." Scandinavian Journal of Disability Research 12, no. 1 (2010): 19-31.

Shakespeare, Tom, and Nicholas Watson. "The Social Model of Disability: An Outdated Ideology?" In Exploring Theories and Expanding Methodologies: Where We Are and Where We Need to Go, edited by Sharon N. Barnartt and Barbara M. Altman, 9-28. Bingley: Emerald Group Publishing Limited, 2001. Siebers, Tobin. Disability Theory. Ann Arbor: University of Michigan Press, 2008. Silvers, Anita. "On the Possibility and Desirability of Constructing a Neutral Conception of Disability." Theoretical Medicine and Bioethics 24, no. 6 (November 2003): 471-87.

Stone, Sharon Dale. "Reactions to Invisible Disability: The Experiences of Young Women Survivors of Hemorrhagic Stroke." Disability and Rehabilitation 27, no. 6 (2005): 293-304.

Terzi, Lorella. "Vagaries of the Natural Lottery? Human Diversity, Disability, and Justice: A Capability Perspective." In Brownless and Cureton, Disability and Disadvantage, 86-111.

Tremain, Shelley. "On the Government of Disability." Social Theory and Practice 27, no. 4 (October 2001): 617-36.

Ubel, Peter A., and George Loewenstein. "Pain and Suffering Awards: They Shouldn't Be (Just) about Pain and Suffering." The Journal of Legal Studies 37, no. S2 (2008): S195-S216.

Ubel, Peter A., George Loewenstein, and Christopher Jepson. "Whose Quality of Life? A Commentary Exploring Discrepancies between Health State Evaluations of Patients and the General Public." Quality of Life Research 12, no. 6 (September 2003): 599-607.

Vehmas, Simo. "Ethical Analysis of the Concept of Disability." Mental Retardation 42, no. 3 (June 2004): 209-22.

- "Philosophy and Science: The Axes of Evil in Disability Studies?" The Journal of Medical Ethics 34, no. 1 (February 2008): 21-23.

Wasserman, David, and Adrienne Asch. "Understanding the Relationship between Disability and Well-Being." In Disability and the Good Human Life, edited by Jerome E. Bickenbach, Franziska Felder, and Barbara Schmitz, 139-67. Cambridge: Cambridge University Press, 2014.

Wendell, Susan. The Rejected Body: Feminist Philosophical Reflections on Disability. London: Routledge, 1996.

—. "Unhealthy Disabled: Treating Chronic Illnesses as Disabilities." Hypatia 16, no. 4 (November 2001): 17-33.

World Health Organization. "International Classification of Impairments, Disabilities, and Handicaps." Geneva: World Health Organization, 1980. 